\title{
Urbanization effect on trends in sunshine duration in China
}

\author{
Yawen Wang $^{1}$, Martin Wild ${ }^{2}$, Arturo Sanchez-Lorenzo ${ }^{3}$, and Veronica Manara ${ }^{4,5}$ \\ ${ }^{1}$ School of Atmospheric Sciences, Sun Yat-Sen University, Zhuhai 519082, China \\ ${ }^{2}$ Institute for Atmospheric and Climate Science, ETH Zurich, 8092 Zurich, Switzerland \\ ${ }^{3}$ Instituto Pirenaico de Ecología, Consejo Superior de Investigaciones Científicas (IPE-CSIC), Zaragoza 50059, Spain \\ ${ }^{4}$ Department of Physics, Università degli Studi di Milano, 20133 Milan, Italy \\ ${ }^{5}$ Institute of Atmospheric Sciences and Climate, ISAC-CNR, Bologna, Italy
}

Correspondence to: Yawen Wang (wangyw53@mail.sysu.edu.cn)

Received: 18 February 2017 - Revised: 9 June 2017 - Accepted: 12 June 2017 - Published: 18 July 2017

\begin{abstract}
There is an ongoing debate on whether the observed decadal variations in surface solar radiation, known as "dimming" and "brightening" periods, are a large-scale or solely local phenomenon. We investigated this issue using long-term sunshine duration records from China, which experienced a rapid increase in urbanization during the past decades. Over the period 1960-2013, 172 pairs of urban and nearby rural stations were analyzed. Urban and rural sunshine duration trends show similar spatial patterns during a dimming phase (1960-1989) and a subsequent period during which trends were leveling off (1990-2013). This indicates that rather than local effects, the trends in sunshine duration are on more of a national or regional scale in China. Nevertheless, in the dimming phase, the declining rate of sunshine duration in rural areas is around two-thirds of that in urban areas. The ratio of rural to urban dimming generally increases from a minimum of 0.39 to a maximum of 0.87 with increasing indices of urbanization calculated based on the year 2013. It reaches a maximum when the urbanization level exceeds $50 \%$, the urban population exceeds 20 million, or the population density becomes higher than 250 person $\mathrm{km}^{-2}$. After the transition into the leveling-off period, sunshine duration trends are no longer significantly affected by urbanization. Meanwhile, the number of laws and regulations related to air pollution and investment in pollution treatment have been increasing in China.
\end{abstract}

Keywords. Meteorology and atmospheric dynamics (climatology; radiative processes)

\section{Introduction}

In line with intensifying anthropogenic disturbances, a decreasing trend in surface solar radiation was noted at widespread locations on the globe between the 1950s and the 1980s with a range of -3 to $-9 \mathrm{Wm}^{-2}$ (Gilgen et al., 1998; Stanhill and Cohen, 2001; Liepert, 2002; Ohmura, 2009; Wild, 2009, 2012). Subsequently, a transition from a decrease to an increase in surface solar radiation occurred in many regions of the world from the mid-1980s on the order of 1 to $4 \mathrm{~W} \mathrm{~m}^{-2}$ (Wild et al., 2005; Wild, 2012, 2016). These phenomena are popularly known as "global dimming and brightening", where "global" originally referred to "global radiation" as a synonym for surface solar radiation but is often interpreted in terms of a global-scale dimension (Wild, 2009, 2012).

Alpert et al. (2005) argued that observed solar dimming is dominated by large urban sites, and thus it is more of a local rather than a global phenomenon. They further estimated that the decreasing rate of solar radiation fluxes accelerates from -0.05 to $-0.32 \mathrm{~W} \mathrm{~m}^{-2} \mathrm{yr}^{-1}$ with population density increasing from 10 to 200 person $\mathrm{km}^{-2}$ (Alpert and Kishcha, 2008). On the other hand, Robaa (2009) observed in Greater Cairo that the dimming rate during the 1969 2006 period is similar for the urban and rural areas at -0.09 and $-0.10 \mathrm{MJ} \mathrm{m}^{-2} \mathrm{yr}^{-1}$, respectively. Further, based on measurements in Israel between 1954 and 2007, Stanhill and Cohen (2009) argued that population density was not a robust proxy for global radiation change. Liley (2009) disputed the conclusions made by Alpert and Kishcha (2008) and deemed that a large anthropogenic effect in the vicinity of a dense population does not negate the finding of long-term 
change in sparsely populated regions; a downward trend of $-0.16 \mathrm{~W} \mathrm{~m}^{-2} \mathrm{yr}^{-1}$ was given in the previous work of Alpert et al. (2005).

To ensure that only urban and rural sites under similar climate conditions are compared, Wang et al. (2014) restricted the analysis to urban-rural station pairs within $2^{\circ} \times 2^{\circ}$ areas and noted that the average urbanization effect on the mean and the trend in surface solar radiation over Europe, China, and Japan from 1961 to 1990 was small. Questioning the existence of an urbanization effect on surface solar radiation trends, Imamovic et al. (2016) further examined the population index (PI) at 157 worldwide sites for the 1960s to the 1980s and concluded that the urbanization effect based on PI is nonsignificant in Europe and Japan but cannot be ruled out in China and Russia. A similar conclusion was made for China by Wang et al. (2012b) using diurnal temperature range (DTR) as a proxy for surface solar radiation. A recent work by Tanaka et al. (2016) used a new approach to infer urbanization by combining population data, historical land use maps, satellite images, and site visit experiences. This further evidenced that the global dimming and brightening phenomenon in Japan was not restricted to urban areas and not primarily driven by local air pollution.

The potential correlation between urbanization and surface solar radiation variation has not only a statistical meaning, but also a physical background. Urbanization, which is accompanied by the industrialization process, plays an important role in producing anthropogenic aerosol and pollutants in the atmosphere. Aerosols can attenuate solar radiation received at the Earth's surface by scattering and absorbing radiation (direct radiative forcing) or by increasing cloud reflectivity and lifetime via acting as cloud condensation nuclei and ice nuclei (indirect radiative forcing; Charlson et al., 1992; Ramanathan et al., 2001; Lohmann and Feichter, 2005; Wild, 2012). Urban areas can be a source of pollutants in distant receptor points and/or a receptor for the long-range transport of pollutants originating at great distances that have a significant effect on the baseline air quality in the receptor areas (National Research Council, 2005). The comparison between urban and rural areas focuses on the first process (Cleveland et al., 1976; Parrish and Zhu, 2009; Zhao et al., 2009).

Population density (PD) is the most widely used index to quantify the impact of urbanization on solar radiation in recent studies (Alpert et al., 2005; Alpert and Kishcha, 2008; Stanhill and Cohen, 2009; Imamovic et al., 2016). Besides $\mathrm{PD}$, this research introduces three other indices to represent the magnitude and process of urbanization: urbanization level (ULE), urbanization speed (USP), and urban population (UP), which are also important indices to measure urbanization and its effects on climate in China (e.g., Zhou and Hansen, 2004; Ren et al., 2008; Yang, 2011).

Sunshine duration is used as a proxy for surface solar radiation. Compared with surface solar radiation, sunshine duration has a much wider spatial and temporal coverage and is almost free of temporal inhomogeneities in China (Xia, 2010; Wang and Yang, 2014; Wang et al., 2015). For example, for the whole of China (latitudes $16^{\circ} 32^{\prime}-52^{\circ} 58^{\prime} \mathrm{N}$ and longitudes $75^{\circ} 14^{\prime}-132^{\circ} 58^{\prime} \mathrm{E}$ ), there are 130 solar radiation stations with only 59 stations covering at least $85 \%$ of the measurement period from 1958 to the present. The majority of surface solar radiation stations are located in urban areas, which will further limit the available data samples for studying urbanization effects. In contrast, there are 906 sunshine duration stations, thus exceeding the solar radiation stations by a factor of about 7 . Of these, 638 have sunshine duration records that cover at least $85 \%$ of the whole measurement period since the 1950s. Moreover, it has been demonstrated that sunshine duration is able to capture variations in cloudiness and, to a lesser extent, the signal from aerosol concentrations (Sanchez-Lorenzo et al., 2009; Wang et al., 2012c; Sanchez-Romero et al., 2014, 2016; Li et al., 2016; Wild, 2016). Similar to the surface solar radiation trends, a transition from decreasing to leveling off was also noted in the sunshine duration trends in China around 1990 (Wang et al., 2013 , 2014). However, an urbanization impact on the trends of sunshine duration remains unclear.

This study will thus make an attempt to examine the urbanization effect on sunshine duration variations in China. The wide temporal and spatial coverage of sunshine duration observations in China provides a unique opportunity to fully understand the differences in sunshine duration trends between rural and urban areas since the 1960s.

\section{Data and methods}

Daily mean meteorological values, based on the datasets of yearly sunshine duration and daily total cloud cover available for the 1960-2013 period, were collected from the China Meteorological Data Sharing Service System (http://data.cma. cn) governed by the China Meteorological Administration (CMA). Basic quality controls on the data (i.e., checks on the climatic range and extreme values, logical rules, and internal and time consistencies) were performed by the CMA (2007). For the yearly dataset, the CMA requires $100 \%$ monthly completeness within the year and $>75 \%$ daily completeness for each month. The instruments for measuring sunshine duration in China are Jordan and Campbell-Stokes sunshine recorders. During the studied period, instrument replacements only occurred in less than $2 \%$ of all meteorological stations (Tao et al., 1997; Wang et al., 2015). Total cloud cover was visually estimated by experienced observers based on the standards of the World Meteorological Organization (WMO).

The dimming and leveling-off phases were defined as the periods 1960-1989 and 1990-2013, respectively, according to the change point in the early 1990s in sunshine duration trends in China evidenced by previous studies (e.g., Xia, 2010; Wang et al., 2013; Hayasaka, 2016; Wang and Yang, 
2014). The year 1990 was also identified as the transition year for the surface solar radiation trend in China (Shi et al., 2008; Tang et al., 2011; Wang and Wild, 2016). This is generally consistent with solar dimming and brightening phases at the global scale (Wild, 2009, 2012).

Urban and rural stations were defined according to the administrative divisions of China. There are five administrative levels of local government: the provincial level (province, autonomous region, municipality, and special administrative region), the prefectural level (prefectural-level city, sub-provincial-level city, autonomous prefecture, prefecture, leagues), the county level (county-level city, citygoverned district, autonomous county, county), the township level (subdistrict, county-level district, town, township), and the village level (neighborhood, community, village; http://www.gov.cn/). In this study, meteorological stations located in the provincial- and prefectural-level divisions were defined as urban stations, while those located in county-, township-, and village-level divisions were deemed as rural stations. Special cases are county-level cities and citygoverned districts, which belong to county-level divisions but were considered as urban stations in this study for two reasons. First, a rapidly accelerating process of urbanization can be expected in county-level cities and city-governed districts, which are mainly created by replacing counties. County-level cities and city-governed districts are mainly located in or near prefectural-level cities, and therefore might be frequently influenced by urban pollution or become the source of pollution emissions as a result of industry transfer.

The raw dataset encompasses 906 stations across latitudes $16^{\circ} 32^{\prime}-52^{\circ} 58^{\prime} \mathrm{N}$, longitudes $75^{\circ} 14^{\prime}-132^{\circ} 58^{\prime} \mathrm{E}$, and elevations $2-4800 \mathrm{~m}$. Only stations with sunshine duration records covering at least $85 \%$ ( $\geq 45$ years) of the period 1960-2013 were considered. The pairing method was then applied to yield a set of proximate urban-rural station pairs in order to avoid biases introduced by differences in the prevailing climate regime, geographical location, and other possible factors. In this way, potential differences in the trends can be more directly related to urban effects. The urbanrural station pairs were strictly selected for each of the 28 studied provincial-level divisions across China, including 22 provinces across mainland China, 5 autonomous regions, and 1 municipality (Chongqing; Fig. 1) depending on (1) the administrative divisions (i.e., the selected county is under the jurisdiction of the corresponding city) and/or (2) the location (i.e., the urban-rural station pairs are within $1^{\circ} \times 1^{\circ}$ with similar elevation). Here the criterion of administrative division was added to further ensure a similar geographical and developmental background for the selected urban-rural station pairs. The administrative division for China was made with full consideration of the principles of the politics, economics, ethnics, demographics, historical traditions, topography, geomorphology, and other related factors. The three municipalities of Beijing, Shanghai, and Tianjin, where only urban stations meet the criterion of having $\geq 45$ years of available data, were excluded from this study due to a lack of corresponding rural stations. The pairing method thus ensures an appropriate comparison of rural and urban trends under similar conditions.

Finally, 172 urban-rural station pairs all over China were selected with an average difference of $95 \mathrm{~m}$ in elevation and a negligible difference in average latitude $\left(\sim 0.001^{\circ} \mathrm{N}\right)$ and longitude $\left(\sim 0.002^{\circ} \mathrm{E}\right.$; Fig. 1). Records from 19 of the selected stations $(\sim 5.5 \%$ of total) were completed based on combining colocated stations with similar climatic and administrative conditions. After taking this into account, 98 and $94 \%$ of the selected stations have $\geq 50$ years of available data for sunshine duration and total cloud cover, respectively. Data gaps in stations with fewer than 3 years of missing data were filled using a linear regression relationship calibrated separately for the 1960-1989 and 1990-2013 periods for each station by means of the available data. This aimed at enabling a comparison in each pair of urban-rural stations for each year without changing the original trend slope. Data gaps in stations with more than 3 years of missing data were filled using the data from the nearest station located in the same administrative level. Specifically, each missing value was estimated by multiplying the corresponding value in the reference station by the ratio of the mean value in the test station to that in the reference station calculated over the period with available data for both stations. In this way, the effect of the different geographic locations of the test and reference stations on the gap-filled data was reduced.

The urban and total population of mainland China and each provincial division for 1960-2013 was collected from the China Statistical Yearbook, the China Compendium of Statistics, and the statistical yearbooks of each province. Then, for each province, the indices ULE, PD, and USP were calculated to quantitatively define urbanization. Urbanization level (ULE; \%) is determined as follows:

$\mathrm{ULE}=\frac{\mathrm{UP}}{\mathrm{TP}} \times 100 \%$,

where UP and TP are urban and total populations, respectively. Population density (PD; person $\mathrm{km}^{-2}$ ) is calculated as

$\mathrm{PD}=\frac{\mathrm{TP}}{\mathrm{LA}}$,

where TP and LA are total population and land area $\left(\mathrm{km}^{2}\right)$, respectively. The speed of urbanization (USP; $\% \mathrm{yr}^{-1}$ ) is computed as follows:

$\mathrm{USP}=\frac{1}{n} \times\left(\mathrm{ULE}_{t+n}-\mathrm{ULE}_{t}\right)$,

where $n$ is the number of years and $\mathrm{ULE}_{t}$ and $\mathrm{ULE}_{t+n}$ are the urbanization levels for the years $t$ and $t+n$, respectively. During the 1980s, the standard for calculating population in China was changed from registered to permanent residents. This might affect the accuracy of the calculated USP 


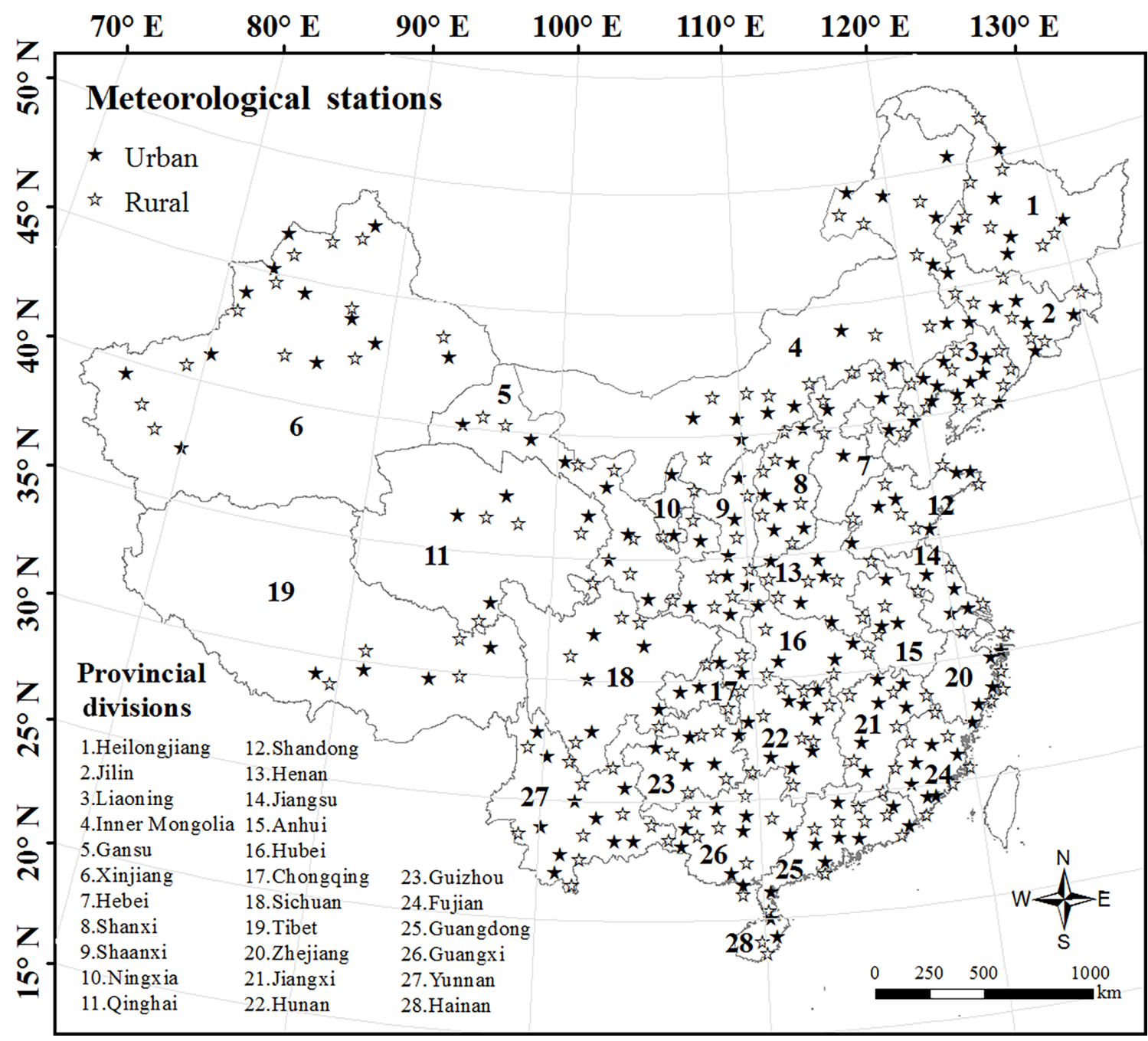

Figure 1. Geographic distribution of the studied 344 meteorological stations over the 28 provincial-level divisions (labeled by numbers) across China. There are 172 urban sites $(\star)$ across latitudes $19^{\circ} 14^{\prime}-50^{\circ} 24^{\prime} \mathrm{N}$, longitudes $75^{\circ} 59^{\prime}-130^{\circ} 18^{\prime} \mathrm{E}$, and elevations $2-3836 \mathrm{~m}$ and 172 corresponding rural sites ( 5 ) across latitudes $18^{\circ} 30^{\prime}-51^{\circ} 43^{\prime} \mathrm{N}$, longitudes $77^{\circ} 16^{\prime}-130^{\circ} 15^{\prime} \mathrm{E}$, and elevations $2-4200 \mathrm{~m}$.

for the 1960-2013 period, but it still works for comparisons among the regions and provinces. There is one exception in the provincial USP calculation: Chongqing and Sichuan were considered together because Chongqing was previously part of Sichuan, and the population of Chongqing and Sichuan cannot be separated before 1997.

\section{Results and discussion}

\subsection{Is sunshine dimming and leveling off in China a local phenomenon?}

To address the question of whether sunshine dimming and leveling off in China are local or national larger-scale phenomena, 172 rural-urban station pairs across China were examined for 1960-2013 (Fig. 2). From Fig. 2a it can be seen that sunshine duration declines at about $90 \%$ of the urban stations in the dimming phase, suggesting a nationwide urban dimming. Sunshine dimming is not limited to urban areas and is also noticeable in rural areas. Figure $2 \mathrm{~b}$ shows that decreasing sunshine duration trends also cover about $80 \%$ of the rural stations. The main regions that deviate from the decreasing tendency in the first period in both urban and rural areas are the Qinghai-Tibet Plateau and northeastern China, where water vapor and deep cloud cover were identified as critical regulators (Wang et al., 2011; Yang et al., 2012). Rural and urban dimming occur in most of China and generally in the same regions, indicating that sunshine dimming in China is more of a large-scale than a local phenomenon. This conclusion can be further verified from Fig. 3a, which shows that there is a large overlap $(\approx 86 \%)$ between rural and urban sunshine duration change rates. On average, sunshine duration significantly $(p<0.05)$ declined in both ur- 
Urban
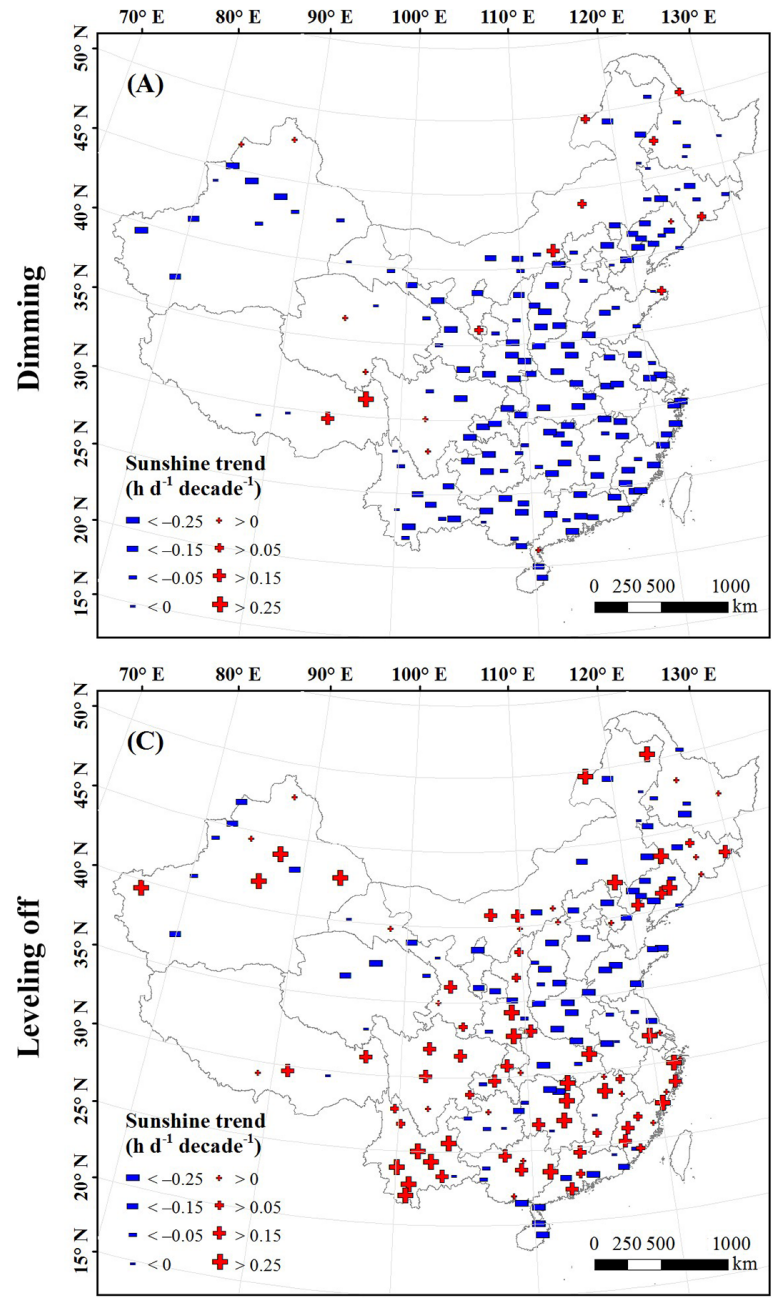

Rural
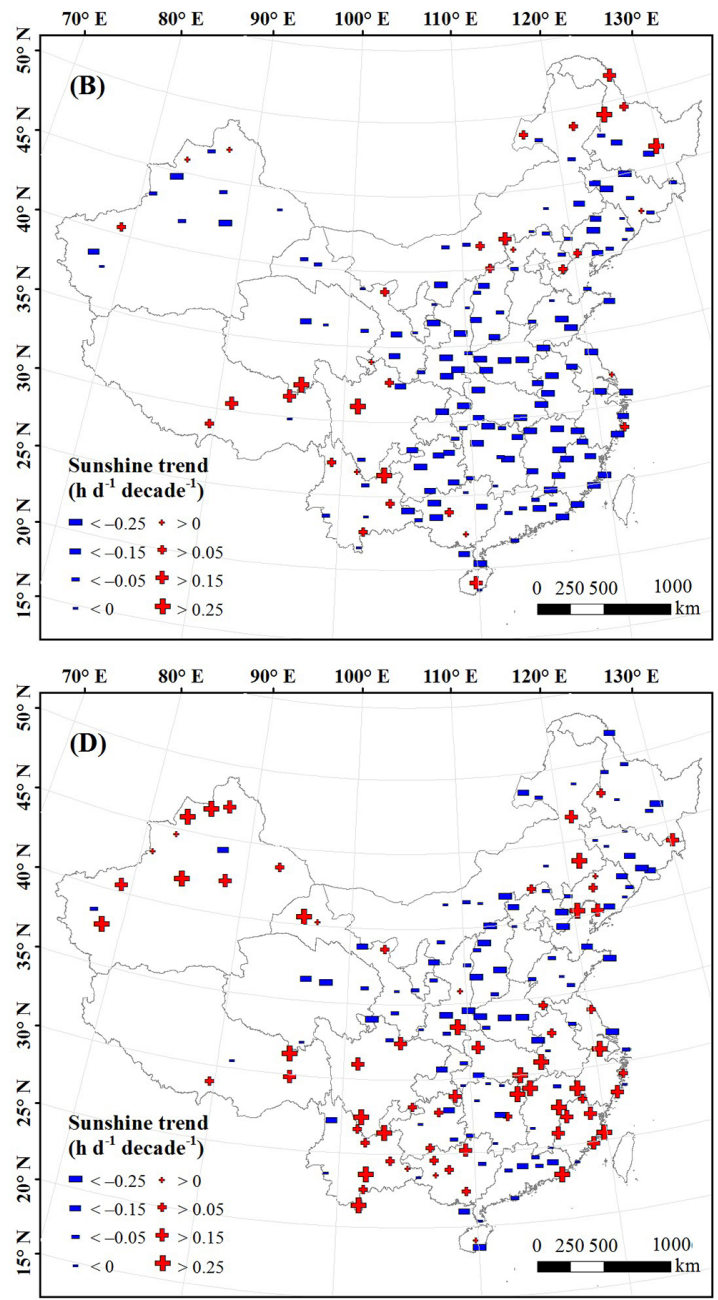

Figure 2. Spatial comparisons of sunshine duration trends $\left(\mathrm{hd}^{-1}\right.$ decade $\left.^{-1}\right)$ between urban and rural stations for the dimming (1960-1989) and leveling-off (1990-2013) phases. (a) Urban trends in the dimming phase, (b) rural trends in the dimming phase, (c) urban trends in the leveling-off phase, (d) and rural trends in the leveling-off phase. The blue minus signs indicate decreasing trends in sunshine duration, while the red plus signs indicate increasing trends in sunshine duration. The bigger the signs, the more significant the magnitudes of the changes.

ban and rural areas at the rate of $-0.20 \pm 0.04 \mathrm{hd}^{-1}$ decade $^{-1}$ and $-0.14 \pm 0.04 \mathrm{hd}^{-1} \mathrm{decade}^{-1}$, respectively (Fig. 4a). The averaged urban dimming rate in China is slightly lower than that obtained in previous studies (Wang et al., 2013; Wang and Yang, 2014) because a few megacities without available nearby rural stations were excluded from this study. Dimming in rural and sparsely populated areas was also noted in Europe, Japan, New Zealand, Egypt, and the greater Tel Aviv region by previous studies (e.g., Liley, 2009; Robaa, 2009; Stanhill and Cohen, 2009; Sanroma et al., 2010; Wang et al., 2014; Tanaka et al., 2016).

Unlike in the dimming phase during which the decline in sunshine duration is distributed almost nationwide, China's sunshine duration trends since 1990 depict a more complex spatial pattern. From Fig. 2c and d it can be inferred that in this period an increase in sunshine duration occurs in about half of China, especially in the southern, northwestern, and northeastern regions, while a decrease continues in the other half, especially in the North China Plain, where an increase in haze pollution is being reported (e.g., Zhao et al., 2011; Wang et al., 2014c; Cao et al., 2015). This spatial pattern of sunshine duration trends is obtained for both rural and urban areas, suggesting a regional rather than local phenomenon. About $84 \%$ of the rural and urban sunshine duration changing rates overlap in the 1990-2013 period (Fig. 3b). Averaged over China, the sunshine duration trend in both urban and rural stations levels off to $-0.01 \pm 0.03 \mathrm{hd}^{-1}$ decade $^{-1}$ for 1990-2013 (Fig. 4a).

In summary, the "global dimming" phenomenon in China is not dominated by large urban sites; it is also evident in rural areas, showing a significant decline for both urban and rural sunshine duration. Similarly, during the leveling-off period 

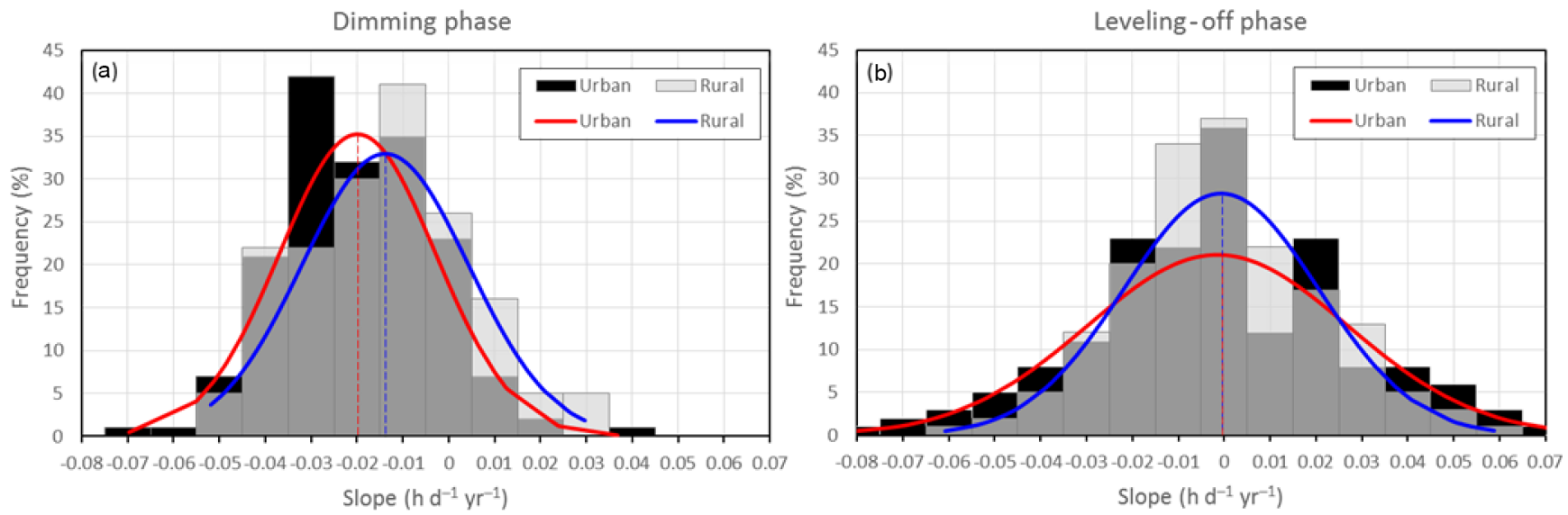

Figure 3. Frequency distribution histograms of urban (black bars) and rural (transparent light gray bars) sunshine duration trend slopes ( $\mathrm{h}^{-1} \mathrm{yr}^{-1}$ ) for the dimming (1960-1989) and leveling-off (1990-2013) phases. The dark gray parts of the bars are the overlaps of the frequency distributions for urban and rural trend slopes. The red and blue solid lines are the expected normal distribution of the trend slopes for urban and rural stations, respectively, while the dashed lines indicate the means.

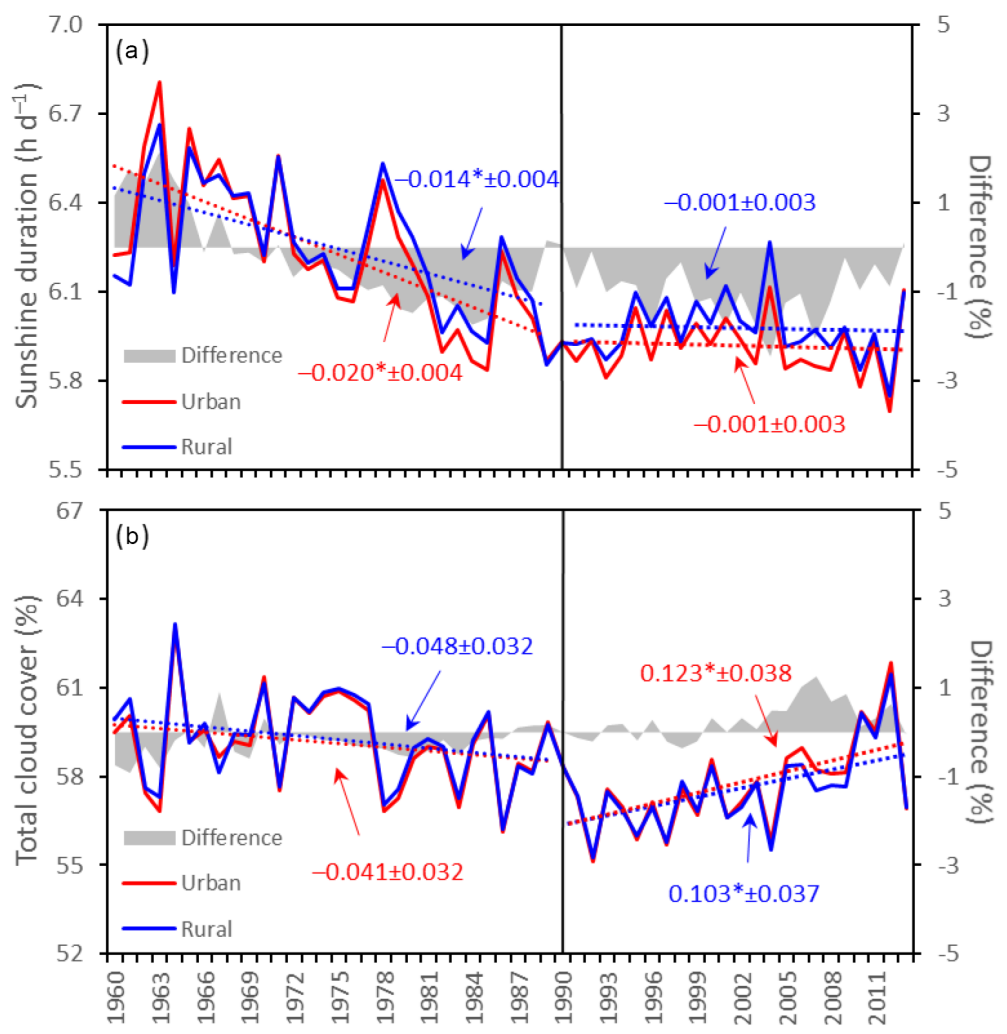

Figure 4. Comparisons of annual trends in average daily sunshine duration $\left(\mathrm{hd}^{-1} ; \mathbf{a}\right)$ and total cloud cover $(\%$; b) between urban and rural areas and the differences (\%) for the dimming (1960-1989) and leveling-off (1990-2013) phases in China. The values indicate the trend slopes and corresponding standard errors. Significant trends at the $95 \%$ confidence level are indicated with a *.

after 1990, sunshine duration recovery happened not only in rural areas, which are assumed to be less developed and polluted, but also in big cities. Therefore, it can be concluded that sunshine dimming and leveling off in China are more large-scale rather than local phenomena.

\subsection{Evidence of urbanization effects on sunshine variations in China}

The urbanization process is accompanied by an increase in energy consumption, industrial GDP (gross domestic prod- 

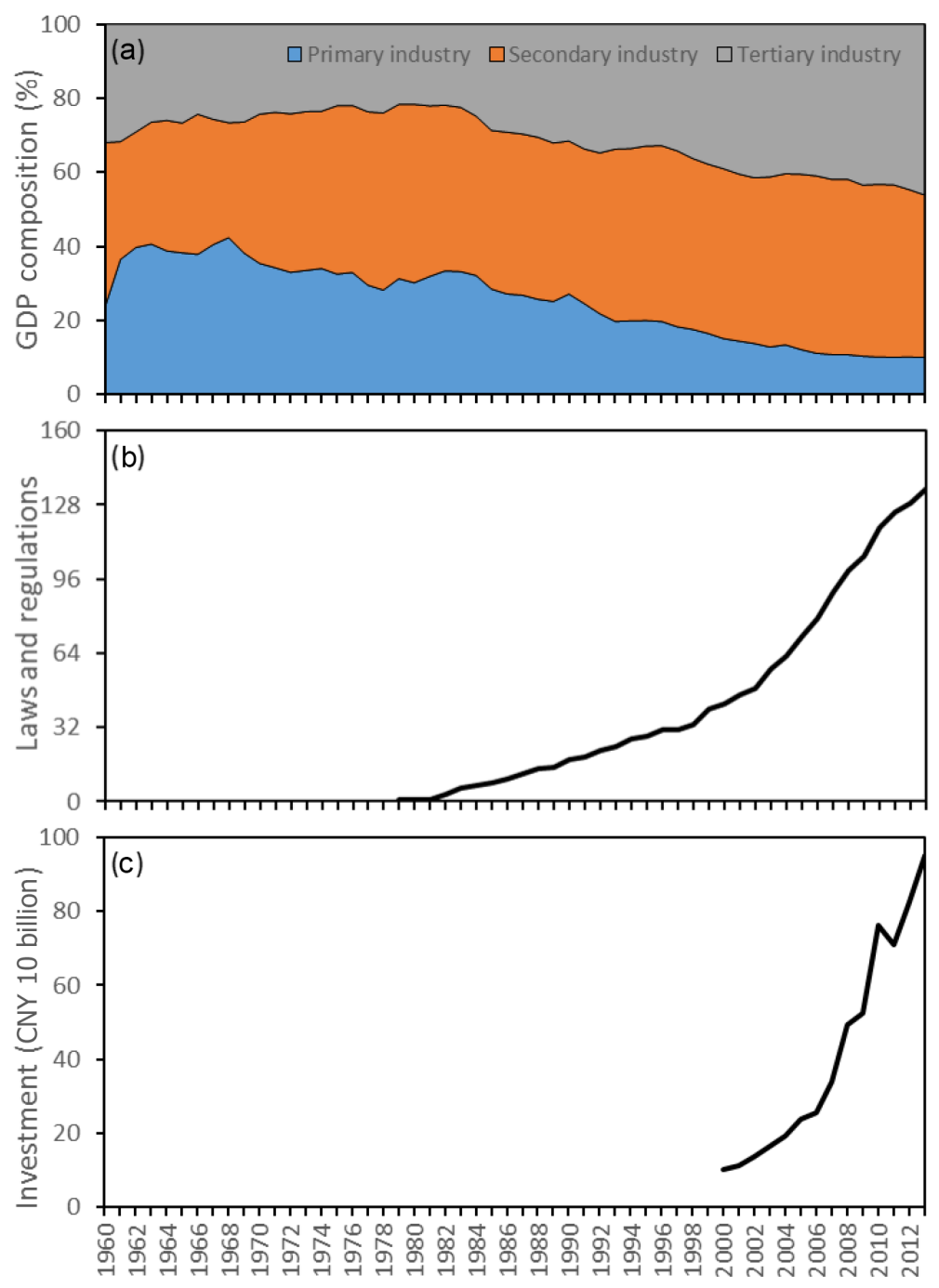

Figure 5. Annual trends in GDP composition (\%; a), accumulated number of laws and regulations related to air quality protection (b), and investment in the treatment of environmental pollution (CNY 10 billion; c) for 1960-2013 in China. Data for GDP composition and investment in the treatment of environmental pollution (available only from 2000 onward) are from the China Statistical Yearbook. Detailed information on the environmental laws and regulations is given by the data center of the Ministry of Environmental Protection of the People's Republic of China (datacenter.mep.gov.cn).

uct), and civil vehicles (Table 1), which are the major anthropogenic sources of air pollution emissions. For 19602013, urbanization continuously progressed in China, which was in line with the social and economic developments. In the dimming phase between 1960 and 1989, China experienced a boom in population and industrialization. China's population rapidly increased with an almost linear trend by 166 million persons decade ${ }^{-1}$. An increasing urbanization process during the dimming phase can also be inferred from the GDP composition trends (Fig. 5a). The portion of the secondary sector in China's GDP largely increased by $4.2 \%$ decade $^{-1}$ during the period 1960-1989. Meanwhile, the primary sector decreased by $3.8 \%$ decade $^{-1}$. This suggests a transition from the primary to the secondary sector.
The secondary sector, which contributed up to $48 \%$ to the total GDP, became the backbone of China's booming economy at this stage. The industrial growth during this period was extensively characterized by low efficiency in energy use (Zhang, 2005; Fei et al., 2011). Environmental protection was seldom of concern in this period, and the first law with possible effects on air quality protection was issued only after 1978; the number of such laws gradually increased to 15 by 1989 (Fig. 5b). This indicates a beginning, even if not a very efficient one, of pollution control. Therefore, we can speculate that this increase in the urbanization process during the dimming period is the reason for the difference noted in urban and rural sunshine duration trends, which declined by $0.20 \pm 0.04$ and $0.14 \pm 0.04 \mathrm{hd}^{-1} \mathrm{decade}^{-1}$, respectively 
Table 1. Pearson correlations between variations in urbanization level (ULE) and energy consumption, gross domestic product (GDP), and civil vehicles for 1960-2013 in China based on the China Statistical Yearbook.

\begin{tabular}{lc}
\hline Variables & $\begin{array}{c}\text { Correlations with } \\
\text { urbanization level }\end{array}$ \\
\hline Total energy consumption & $0.980^{*}$ \\
Coal & $0.981^{*}$ \\
Crude oil & $0.983^{*}$ \\
Natural gas & $0.877^{*}$ \\
Power & $0.952^{*}$ \\
\hline GDP & $0.909^{*}$ \\
Industrial & $0.918^{*}$ \\
\hline Civil vehicles & $0.872^{*}$ \\
\hline
\end{tabular}

* Significant at the $99 \%$ confidence level.

(Fig. 4a). The decreasing trend in sunshine duration in rural areas might be related to the baseline pollution generated by urban areas from distant regions and/or changes in cloud properties other than cover. Meanwhile, urban and rural total cloud cover slightly decreased by $0.41 \pm 0.32$ and $0.48 \pm 0.32 \%$ decade $^{-1}$, respectively (Fig. $4 b$ ), which thus cannot explain the decreasing trend in sunshine duration. The differences in total cloud cover between urban and rural areas mainly stay negative with absolute values smaller than $1 \%$, which cannot be the reason for the inverse evolution in the difference between urban and rural sunshine duration. Nevertheless, it is worth mentioning that total cloud cover changes may not represent the full cloud radiative effect.

In the leveling-off phase between 1990 and 2013, the population continued to increase in China. The primary sector only accounted for $\sim 10 \%$ of total GDP in the year 2013, further indicating a more urbanized status. However, the increasing urbanization process did not result in a stronger decrease in sunshine duration. In contrast, it resulted in an overall leveling off by $-0.01 \pm 0.03 \mathrm{hd}^{-1}$ decade $^{-1}$ in both rural and urban areas (Fig. 4a). Meanwhile, the total cloud cover trend in urban and rural areas significantly recovered by $1.23 \pm 0.38$ and $1.03 \pm 0.37 \%$ decade $^{-1}$, respectively (Fig. 4b), thus not contributing to the slowdown of the declining trend in sunshine duration. The lack of a trend in sunshine duration could still be due to the effects of clouds not included in the cloud cover variable. In fact, it seems that clouds play a more significant role in this period compared to the previous decades (e.g., Folini and Wild, 2015); this is indicated in Fig. 4. The positive difference between urban and rural total cloud cover after 2000, especially for the period 2006-2009 when the difference is greater than $0.5 \%$, might help to enlarge the difference between urban and rural sunshine duration. Nevertheless, it is beyond the scope of this study to examine the local cloud effects on the mean values of sunshine duration in
China. Considering the lacking difference in sunshine duration trends between rural and urban areas, this result indicates an insignificant urbanization effect on sunshine duration in this period. Effective air pollution regulations after 1990 are indicated in Fig. 5b; the number of laws and regulations related to air pollution rapidly increased to 135 by the year 2013. The investment total in the treatment of environmental pollution in China in 2013 (CNY 952 billion) was 9.4 times that in 2000 (CNY 101 billion; Fig. 5c). A slowdown in the increasing trend of total population to a rate of 92 million persons decade ${ }^{-1}$ was also noted for the period 1990-2013 when the one-child policy was implemented in China. In addition, the tertiary sector, which contributes less to air pollution than the secondary sector, grew in China during 1990-2013 and contributed as much as the secondary sector to the national economy (Fig. 5a). National pollution control efforts may have helped to offset anthropogenic air pollution induced during the urbanization process since the 1990s, thereby reducing the urban effect in sunshine duration records. In line with this result, the trend in aerosol optical depth (AOD) simulated by the GOCART global chemical transport model decreased between the mid-1990s and 2000s in China (Streets et al., 2008), as did black carbon emissions (Folini and Wild, 2015). A consistent decline in $\mathrm{PM}_{2.5}$ and $\mathrm{PM}_{10}$ concentrations was noted in the 2000s (Lei et al., 2011; Wang et al., 2012a, 2013). However, using TOMS AOD at $500 \mathrm{~nm}(1980-2001)$ along with MODIS AOD at $550 \mathrm{~nm}$ (2000-2008), Guo et al. (2011) observed a continuous upward trend in average AOD over eight typical regions across China without any transition in 1990. A significant increment of aerosol single-scattering albedo was reported in China between the early 1980s and 1998, which could result in less absorption and thus more radiation reaching the Earth's surface (Qian et al., 2007). The difference in the trends between PM concentrations and satellite AOD might be explained by the emission control policies in China, which target primary aerosols (mainly related to PM) but are less strict for secondary aerosol precursors (e.g., $\mathrm{NO}_{x}, \mathrm{NMVOC}$, and $\mathrm{NH}_{3}$, mainly related to AOD; Lin et al., 2010). In general, in the dimming phase without effective pollution regulations, the emissions generated during the urbanization process were directly changed into equivalent pollutants. On the other hand, in the subsequent leveling-off phase, the increasing emissions were possibly compensated for by the clean air policies and investments; thus urbanization no longer simply meant an increase in air pollution, and its urban effect on sunshine duration variations became insignificant.

Overall, urbanization effects on sunshine duration variations are present in the dimming phase in China, which is consistent with the findings by Wang et al. (2012b) based on DTR and Imamovic et al. (2016) based on surface solar radiation records. The difference in urban and rural cloud cover trends remains similar over this period, which would not cause a widening urban-rural contrast in sunshine duration. The average difference in latitude, longitude, and eleva- 

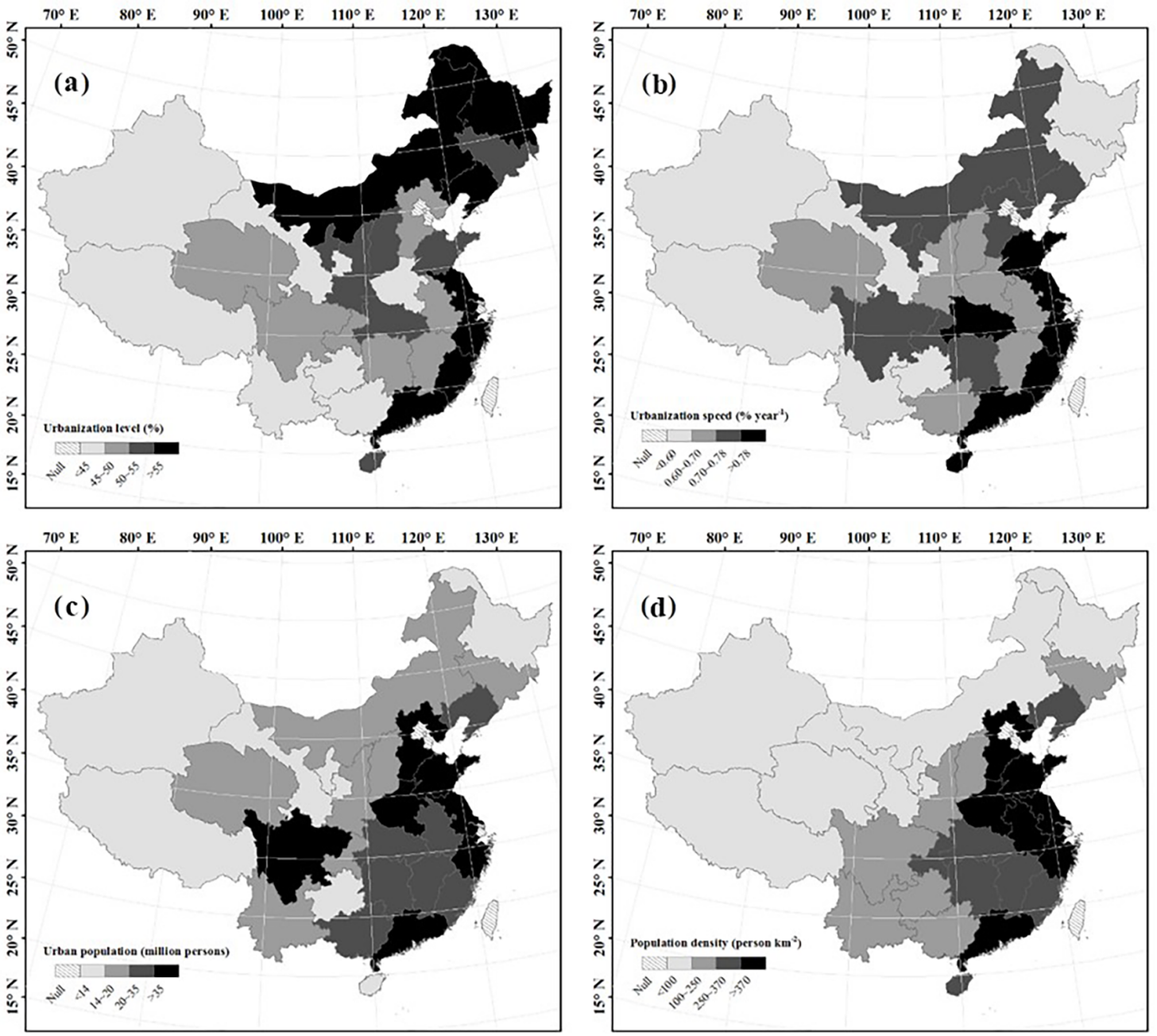

Figure 6. Spatial comparisons of urbanization level (a; \%), urbanization speed $\left(\mathbf{b} ; \% \mathrm{yr}^{-1}\right)$, urban population (c; million persons), and population density (d; person $\mathrm{km}^{-2}$ ) for the 28 provincial-level divisions across China. Urbanization level, urban population, and population density are calculated with respect to the year 2013. Urbanization speed is calculated for the period 1960-2013. The cutoff points are chosen based on the quantile method.

tion between the selected urban and rural stations also would not lead to a varying difference in rural and urban sunshine duration. The urbanization effect on sunshine duration is less significant after 1990. The conclusion of an insignificant urbanization effect after 1990 differs from that made by Wang et al. (2012b) based on DTR in China. They found a decreasing trend in urban DTR and an increasing trend in rural DTR in the brightening phase, in which urban and rural areas are represented by 71 large cites, 234 small cities, and 97 rural stations defined by an urban population of (UP) $\geq 0.5,0.05$ 0.5 and $<0.05$ million persons, respectively. Rural and urban stations defined in the study by Wang et al. (2012b) are not equally distributed across China with most rural stations in the western part and most urban stations in the eastern part. They are thus faced with quite different conditions in terms of climate and development. The reason for the recent level- ing off in the sunshine duration trend in China is still an open question and needs further discussion and more detailed investigations of the urbanization effect in the different regions. Besides cloud cover, which contains uncertainties due to subjective observations, the cloud type and physical and radiative properties should also be fully considered. Effects from other potential driving factors, such as surface albedo, water vapor, and wind speed, need to be clarified. The effectiveness of the environmental laws and regulations still requires further exploration.

\subsection{Quantifying urbanization effects on rural and urban sunshine dimming}

After clarifying the existence of urbanization effects on sunshine duration in the dimming phase, we attempted to further quantify them. For this purpose, China was divided into re- 

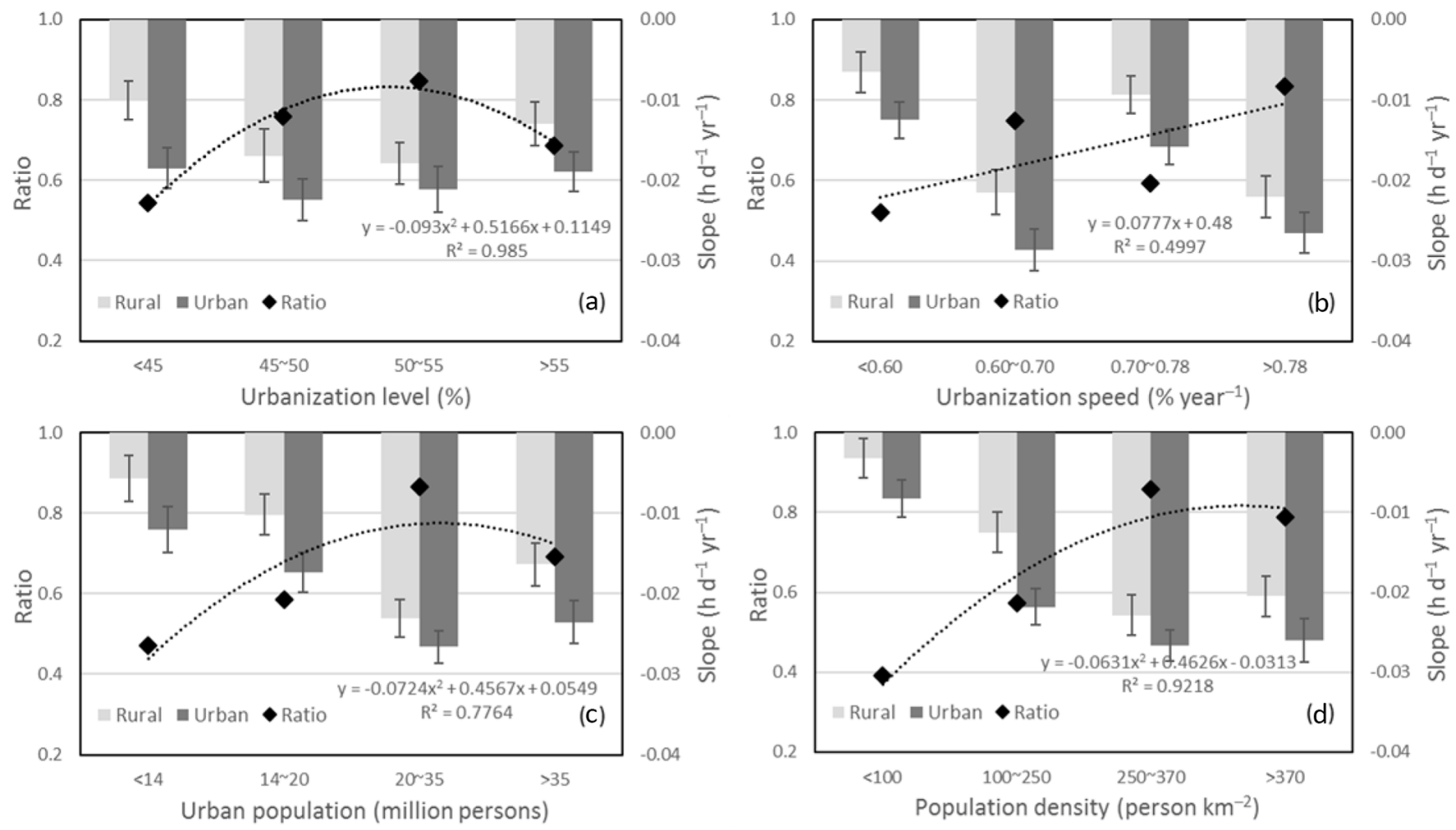

Figure 7. Ratios of the rural to urban trend slopes for sunshine duration $\left(\mathrm{hd}^{-1} \mathrm{yr}^{-1}\right)$ in different ranges of urbanization level (a; \%), urbanization speed $\left(\mathbf{b} ; \% \mathrm{yr}^{-1}\right)$, urban population (c; million persons), and population density (d; person $\mathrm{km}^{-2}$ ) in $\mathrm{China}$ for the dimming phase of 1960-1989. The cutoff points are chosen based on the quantile method.

gions with different scales of urbanization level (ULE), urbanization speed (USP), urban population (UP), and population density (PD; Fig. 6). The cutoff points were chosen based on the quantile method in order to ensure an equal number of provinces in each divided scale. The ULE, UP, and PD for each province were calculated based on the data for 2013, which were assumed to reflect the general conditions of each province for the past decades for comparison.

Comparing Fig. $2 \mathrm{a}$ and $\mathrm{b}$ with Fig. 6 shows that the strongest declines in sunshine duration trends in the dimming phase occur in the urbanized regions (southeast part), while some exceptions with increasing trends are mainly located in less urbanized regions (southwest and northeast parts). This is further illustrated in Fig. 7, which shows that the dimming rate in both urban and rural sunshine duration initially strengthens with increasing ULE, UP, and PD but decreases when ULE $>50 \%$, UP $>20$ million persons, or $\mathrm{PD}>250$ person $\mathrm{km}^{-2}$. Sunshine dimming shows a different relation with USP, which is the only index taking the urbanization conditions in the 1960s into account. Figure 7b shows that rural and urban dimming strengthens when USP increases from $<0.6$ to $0.6-0.7 \% \mathrm{yr}^{-1}$, but clearly weakens when USP further increases to $0.70-0.78 \% \mathrm{yr}^{-1}$ and then restrengthens when USP is greater than $0.78 \% \mathrm{yr}^{-1}$. The reason for the main exception in the USP category of 0.70
$0.78 \% \mathrm{yr}^{-1}$ is indicated in Fig. 6, which shows that half of the provinces with a USP of $0.70-0.78 \% \mathrm{yr}^{-1}$ have an urbanization level only of $45-50 \%$ in 2013 . Therefore, even with a relatively higher USP, these provinces are still less urbanized, and thus a relatively weaker dimming trend can be noted (Fig. 2).

On average, the decline in sunshine duration in rural areas $\left(-0.14 \mathrm{hd}^{-1} \mathrm{decade}^{-1}\right)$ is about two-thirds of that in urban areas $\left(-0.20 \mathrm{hd}^{-1}\right.$ decade $\left.^{-1}\right)$ in the dimming phase (Fig. 4a). This ratio changes with different scales of ULE, UP, and PD in a quadratic function with a parabola opening downward (Fig. 7). The ratio of rural to urban dimming gradually changes from 0.54 to 0.85 when ULE increases from $<45$ to $50-55 \%$. It changes from 0.47 to 0.87 when UP increases from $<14$ to $20-35$ million persons and from 0.39 to 0.86 when PD increases from $<100$ to $250-370$ person $\mathrm{km}^{-2}$; afterwards it slightly decreases with further increases in these urbanization indices. By contrast, the rural-urban dimming ratio generally shows a linear relation with USP, changing from 0.52 to 0.83 with USP accelerating from $<0.60$ to $>0.78 \% \mathrm{yr}^{-1}$ due to the decrease in the ratio in the USP category of $0.70-0.78 \% \mathrm{yr}^{-1}$.

With increasing urbanization, rural dimming generally becomes closer to urban dimming, possibly due to industrial transfer $(\mathrm{Li}, 2010)$ and wind dispersion of pol- 
lutants and aerosols from urban to nearby rural areas (Yang et al., 2009; Wang et al., 2014b). This effect provides maximum ratio values when urbanization reaches certain levels (ULE > 50\%; UP > 20 million persons; PD > 250 person $\mathrm{km}^{-2}$ ), above which a further increase in urbanization will not generate further alignment of urban and rural dimming or a further strengthening of these trends. This might be due to improved air quality in the most urbanized regions. Similarly, Imamovic et al. (2016) questioned the existence of a population-based urbanization effect on surface solar radiation in the highly urbanized regions of Europe and Japan but suggested that such an effect cannot be ruled out in Russia and China.

\section{Conclusions}

Based on sunshine duration data from 344 sites across China, the effect of urbanization on sunshine duration was evaluated from 1960 to 2013. A dimming phase during the 1960-1980 period was proven to be of large (national) scale in China based on three lines of evidence: (1) the declining trend in sunshine duration in China was significant in both rural and urban areas in the dimming phase; (2) spatially, negative sunshine duration trends cover about $90 \%$ of the 172 urban stations and $80 \%$ of the 172 nearby rural stations; (3) and the rates of sunshine duration changes between the selected rural and urban stations across China largely overlap by $86 \%$. During the leveling-off phase in the 1990-2013 period, the positive and negative sunshine duration trends respectively cover about half of China and are almost equally distributed in both rural and urban areas, suggesting a regional phenomenon of sunshine duration variations. In addition, the changing rates of rural and urban sunshine duration overlap by about $84 \%$ in the $1990-2013$ period. Therefore, the decadal variations in sunshine duration in China are evident on a large spatial scale.

It seems that sunshine duration variations are sensitive to changes in urbanization in the dimming phase. Averaged for the whole of China, rural dimming is two-thirds of urban dimming, indicating an overestimation of China's dimming when only urban-scale sunshine duration sites are considered. The overall ratio changes from the minimum of 0.39 to the maximum of 0.87 under different urbanization conditions. It generally increases in more urbanized regions where rural areas might be influenced by urban pollution and reaches a maximum value when urbanization reaches certain levels (urbanization level $>50 \%$; urban population $>$ 20 million persons; population density $>250$ person $\mathrm{km}^{-2}$ ). The ratio of rural to urban dimming shows a quadratic relation (parabola opening downward) with urbanization, quantified by the indices of urbanization level, urbanization population, and population density.

During the leveling-off period after 1990, air pollutants generated in the urbanization process might have been par- tially counteracted by the increasing regulations and investments in the abatement of environmental pollution. As a consequence, urbanization effects on sunshine duration trends became nonsignificant.

Data availability. The meteorological data used in this study are from the China Meteorological Data Sharing Service System (http: //data.cma.cn).

Competing interests. The authors declare that they have no conflict of interest.

Acknowledgements. The paper is funded by the National Key Basic Research Program of China (2016YFA0602701) and the National Natural Science Foundation of China (grant no. 41501036). The co-author Arturo Sanchez-Lorenzo is supported by a postdoctoral fellowship JCI-2012-12508 and projects CGL2014-55976-R and CGL2014-52135-C3-1-R financed by the Spanish Ministry of Economy and Competitiveness. Dimming and brightening research at ETH Zurich has been supported by the Swiss National Science Foundation (grant nos. 200021135395 and 200020 159938) and ETH research grant $\mathrm{CH} 2-0111-1$. The authors would also like to thank Yonghui Yang, Dandan Ren, and Qiuli Hu for their strong support of this research.

The topical editor, Vassiliki Kotroni, thanks two anonymous referees for help in evaluating this paper.

\section{References}

Alpert, P., Kishcha, P., Kaufman, Y. J., and Schwarzbard, R.: Global dimming or local dimming?: Effect of urbanization on sunlight availability, Geophys. Res. Lett., 32, L17802, https://doi.org/10.1029/2005gl023320, 2005.

Alpert, P. and Kishcha, P.: Quantification of the effect of urbanization on solar dimming, Geophys. Res. Lett., 35, L08801, https://doi.org/10.1029/2007GL033012, 2008.

Cao, Z., Sheng, L., Liu, Q., Yao, X., and Wang, W.: Interannual increase of regional haze-fog in North China Plain in summer by intensified easterly winds and orographic forcing, Atmos. Environ., 122, 154-162, 2015.

Charlson, R. J., Schwartz, S. E., Hales, J. M., Cess, R. D., Coakley, J. A., Hansen, J. E., and Hofmann, D. J.: Climate forcing by anthroogenic aerosols, Science, 255, 423-430, 1992.

Cleveland, W., Kleiner, B., McRae, J., and Warner, J.: Photochemical air pollution: transport from the New York City area into Connecticut and Massachusetts, Science, 191, 179-181, 1976.

CMA: Specifications for surface meteorological observation, in: Part 22: Quality Control of Data, China Meteorological Press, Beijing, 2007.

Fei, L., Dong, S., Xue, L., Liang, Q., and Yang, W.: Energy consumption-economic growth relationship and carbon dioxide emissions in China, Energ. Policy, 39, 568-574, 2011.

Folini, D. and Wild, M.: The effect of aerosols and sea surface temperature on China's climate in the late twentieth century from en- 
sembles of global climate simulations, J. Geophys. Res.-Atmos., 120, 2261-2279, https://doi.org/10.1002/2014JD022851, 2015.

Gilgen, H., Wild, M., and Ohmura, A.: Means and trends of shortwave irradiance at the surface estimated from global energy balance archive data, J. Climate, 11, 2042-2061, 1998.

Guo, J. P., Zhang, X. Y., Wu, Y. R., Zhaxi, Y. Z., Che, H. Z., La, B., Wang, W., and Li, X. W.: Spatio-temporal variation trends of satellite-based aerosol optical depth in China during 1980-2008, Atmos. Environ., 45, 6802-6811, https://doi.org/10.1016/j.atmosenv.2011.03.068, 2011.

Hayasaka, T.: The long-term variation in surface shortwave irradiance in China and Japan: a review, J. Meteorol. Soc. Jpn., 94, 393-414, https://doi.org/10.2151/jmsj.2016-024, 2016.

Imamovic, A., Tanaka, K., Folini, D., and Wild, M.: Global dimming and urbanization: did stronger negative SSR trends collocate with regions of population growth?, Atmos. Chem. Phys., 16, 2719-2725, https://doi.org/10.5194/acp-16-27192016, 2016.

Lei, Y., Zhang, Q., He, K. B., and Streets, D. G.: Primary anthropogenic aerosol emission trends for China, 1990-2005, Atmos. Chem. Phys., 11, 931-954, https://doi.org/10.5194/acp-11-9312011, 2011.

Li, J., Liu, R., Liu, S. C., Shiu, C. J., Wang, J., and Zhang, Y.: Trends in aerosol optical depth in Northern China retrieved from sunshine duration data, Geophys. Res. Lett., 43, 431-439, https://doi.org/10.1002/2015GL067111, 2016.

Li, X. L.: Environmental risks of less-developed regions to undertake industrial transfer and the countermeasures, Reform. Strateg., 26, 100-102, 2010.

Liepert, B. G.: Observed reductions of surface solar radiation at sites in the United States and worldwide from 1961 to 1990, Geophys. Res. Lett., 29, 1421, https://doi.org/10.1029/2002gl014910, 2002.

Liley, J.: New Zealand dimming and brightening, J. Geophys. Res.Atmos., 114, D00D10, https://doi.org/10.1029/2008JD011401, 2009.

Lin, J., Nielsen, C. P., Zhao, Y., Lei, Y., Liu, Y., and McElroy, M. B.: Recent changes in particulate air pollution over China observed from space and the ground: effectiveness of emission control, Environ. Sci. Technol., 44, 7771-7776, https://doi.org/10.1021/es101094t, 2010.

Lohmann, U. and Feichter, J.: Global indirect aerosol effects: a review, Atmos. Chem. Phys., 5, 715-737, https://doi.org/10.5194/acp-5-715-2005, 2005.

National Research Council: Urbanization, energy, and air pollution in china: the challenges ahead, National Academies Press, Washington DC, 2005.

Ohmura, A.: Observed decadal variations in surface solar radiation and their causes, J. Geophys. Res., 114, D00D05, https://doi.org/10.1029/2008jd011290, 2009.

Parrish, D. D. and Zhu, T.: Clean air for megacities, Science, 326, 674-675, 2009.

Qian, Y., Wang, W., Leung, L. R., and Kaiser, D. P.: Variability of solar radiation under cloud-free skies in China: the role of aerosols, Geophys. Res. Lett., 34, L12804, https://doi.org/10.1029/2006gl028800, 2007.

Ramanathan, V., Crutzen, P. J., Kiehl, J. T., and Rosenfeld, D.: Atmosphere - aerosols, climate, and the hydrological cycle, Science, 294, 2119-2124, 2001.
Ren, G., Zhou, Y., Chu, Z., Zhou, J., Zhang, A., Guo, J., and Liu, X.: Urbanization effects on observed surface air temperature trends in North China, J. Climate, 21, 1333-1348, 2008.

Robaa, S.: Urban-rural solar radiation loss in the atmosphere of Greater Cairo region, Egypt, Energ. Convers. Manage., 50, 194202, 2009.

Sanchez-Lorenzo, A., Calbó, J., Brunetti, M., and Deser, C.: Dimming/brightening over the Iberian Peninsula: trends in sunshine duration and cloud cover and their relations with atmospheric circulation, J. Geophys. Res.-Atmos., 114, 195-200, 2009.

Sanchez-Romero, A., Sanchez-Lorenzo, A., Calbó, J., González, J. A., and Azorin-Molina, C.: The signal of aerosolinduced changes in sunshine duration records: a review of the evidence, J. Geophys. Res.-Atmos., 119, 4657-4673, https://doi.org/10.1002/2013JD021393, 2014.

Sanchez-Romero, A., Sanchez-Lorenzo, A., González, J. A., and Calbó, J.: Reconstruction of long-term aerosol optical depth series with sunshine duration records, Geophys. Res. Lett., 43, 1296-1305, https://doi.org/10.1002/2015GL067543, 2016.

Sanroma, E., Palle, E., and Sanchez-Lorenzo, A.: Long-term changes in insolation and temperatures at different altitudes, Environ. Res. Lett., 5, 024006, https://doi.org/10.1088/17489326/5/2/024006, 2010.

Shi, G., Hayasaka, T., Ohmura, A., Chen, Z., Wang, B., Zhao, J., Che, H., and $\mathrm{Xu}, \mathrm{L} .:$ Data quality assessment and the longterm trend of ground solar radiation in China, J. Appl. Meteorol. Clim., 47, 1006-1016, 2008.

Stanhill, G. and Cohen, S.: Global dimming: a review of the evidence for a widespread and significant reduction in global radiation with discussion of its probable causes and possible agricultural consequences, Agr. Forest Meteorol., 107, 255-278, 2001.

Stanhill, G. and Cohen, S.: Is solar dimming global or urban? Evidence from measurements in Israel between 1954 and 2007, J. Geophys. Res., 114, D00D17, https://doi.org/10.1029/2009JD011976, 2009.

Streets, D. G., Yu, C., Wu, Y., Chin, M., Zhao, Z., Hayasaka, T., and Shi, G.: Aerosol trends over China, 1980-2000, Atmos. Res., 88, 174-182, https://doi.org/10.1016/j.atmosres.2007.10.016, 2008.

Tanaka, K., Ohmura, A., Folini, D., Wild, M., and Ohkawara, N.: Is global dimming and brightening in Japan limited to urban areas?, Atmos. Chem. Phys., 16, 13969-14001, https://doi.org/10.5194/acp-16-13969-2016, 2016.

Tang, W.-J., Yang, K., Qin, J., Cheng, C. C. K., and He, J.: Solar radiation trend across China in recent decades: a revisit with quality-controlled data, Atmos. Chem. Phys., 11, 393-406, https://doi.org/10.5194/acp-11-393-2011, 2011.

Tao, S., Fu, C., Zeng, Z., and Zhang, Q.: Two Long-Term Instrumental Climatic Data Bases of the People's Republic of China, edited by: Kaiser, D., Oak Ridge National Laboratory, Tennessee, USA, 1997.

Wang, C. H., Zhang, Z. F., and Tian, W. S.: Factors affecting the surface radiation trends over China between 1960 and 2000, Atmos. Environ., 45, 2379-2385, https://doi.org/10.1016/j.atmosenv.2011.02.028, 2011.

Wang, K. C., Dickinson, R. E., Su, L., and Trenberth, K. E.: Contrasting trends of mass and optical properties of aerosols over the Northern Hemisphere from 1992 to 2011, Atmos. Chem. Phys., 12, 9387-9398, https://doi.org/10.5194/acp-129387-2012, 2012a. 
Wang, K., Ye, H., Chen, F., Xiong, Y., and Wang, C.: Urbanization effect on the diurnal temperature range: different roles under solar dimming and brightening, J. Climate, 25, 1022-1027, 2012b.

Wang, K., Ma, Q., Wang, X., and Wild, M.: Urban impacts on mean and trend of surface incident solar radiation, Geophys. Res. Lett., 41, 4664-4668, 2014.

Wang, K., Ma, Q., Li, Z., and Wang, J.: Decadal variability of surface incident solar radiation over China: observations, satellite retrievals, and reanalyses, J. Geophys. Res.-Atmos., 120, 65006514, 2015

Wang, Y., Yang, Y., Zhou, X., Zhao, N., and Zhang, J.: Air pollution is pushing wind speed into a regulator of surface solar irradiance in China, Environ. Res. Lett., 9, 054004, https://doi.org/10.1088/1748-9326/9/5/054004, 2014b.

Wang, Y. S., Yao, L., Wang, L., Liu, Z., Ji, D., Tang, G., Zhang, J., Sun, Y., Hu, B., and Xin, J.: Mechanism for the formation of the January 2013 heavy haze pollution episode over central and eastern China, Science China Earth Sci., 57, 14-25, 2014c.

Wang, Y. and Wild, M.: A new look at solar dimming and brightening in China, Geophys. Res. Lett., 43, 11777-11785, https://doi.org/10.1002/2016GL071009, 2016.

Wang, Y. W., Yang, Y. H., Zhao, N., Liu, C., and Wang, Q. X.: The magnitude of the effect of air pollution on sunshine hours in China, J. Geophys. Res.-Atmos., 117, D00V14, https://doi.org/10.1029/2011jd016753, 2012c.

Wang, Y. W., Yang, Y. H., Han, S. M., Wang, Q. X., and Zhang, J. H.: Sunshine dimming and brightening in Chinese cities (1955-2011) was driven by air pollution rather than clouds, Clim. Res., 56, 11-20, https://doi.org/10.3354/cr01139, 2013.

Wang, Y. W. and Yang, Y. H.: China's dimming and brightening: evidence, causes and hydrological implications, Ann. Geophys., 32, 41-55, https://doi.org/10.5194/angeo-32-41-2014, 2014.

Wild, M., Gilgen, H., Roesch, A., Ohmura, A., Long, C. N., Dutton, E. G., Forgan, B., Kallis, A., Russak, V., and Tsvetkov, A.: From dimming to brightening: decadal changes in solar radiation at Earth's surface, Science, 308, 847-850, https://doi.org/10.1126/science.1103215, 2005.
Wild, M.: Global dimming and brightening: a review, J. Geophys. Res.-Atmos., 114, D00d16, https://doi.org/10.1029/2008jd011470, 2009.

Wild, M.: Enlightening global dimming and brightening, B. Am. Meteorol. Soc., 93, 27-37, https://doi.org/10.1175/bams-d-1100074.1, 2012.

Wild, M.: Decadal changes in radiative fluxes at land and ocean surfaces and their relevance for global warming, WIREs Clim. Change, 7, 91-107, https://doi.org/10.1002/wcc.372, 2016.

Xia, X. A.: Spatiotemporal changes in sunshine duration and cloud amount as well as their relationship in China during 1954-2005, J. Geophys. Res.-Atmos., 115, D00k06, https://doi.org/10.1029/2009jd012879, 2010.

Yang, C.: Urbanization and impact of rural-urban migration on Chinese cities, BMC Ecol., 11, 1-8, 2011.

Yang, K., Ding, B., Qin, J., Tang, W., Lu, N., and Lin, C.: Can aerosol loading explain the solar dimming over the Tibetan Plateau?, Geophys. Res. Lett., 39, L20710, https://doi.org/10.1029/2012GL053733, 2012.

Yang, Y. H., Zhao, N., Hu, Y. K., and Zhou, X. Y.: Effect of wind speed on sunshine hours in three cities in northern China, Clim. Res., 39, 149-157, https://doi.org/10.3354/cr00820, 2009.

Zhang, Z.: Deepening the reform and promoting the transformation of extensive economic growth mode, Econ. Res. J., 11, 4-9, 2005.

Zhao, P., Zhang, X., Xu, X., and Zhao, X.: Long-term visibility trends and characteristics in the region of Beijing, Tianjin, and Hebei, China, Atmos. Res., 101, 711-718, 2011.

Zhao, X., Zhang, X., Xu, X., Xu, J., Meng, W., and Pu, W.: Seasonal and diurnal variations of ambient $\mathrm{PM}_{2.5}$ concentration in urban and rural environments in Beijing, Atmos. Environ., 43, 28932900, 2009.

Zhou, L. and Hansen, J. E.: Evidence for a significant urbanization effect on climate in China, P. Natl. Acad. Sci. USA, 101, 95409544, 2004. 